\title{
Inferior alveolar nerve dysfunction in mandibular fractures: a prospective cohort study
}

\author{
Chandan S N ${ }^{1}$, Sujeeth Kumar Shetty ${ }^{1}$, Sahith Kumar Shetty ${ }^{1}$, Anjan Kumar Shah ${ }^{2}$ \\ ${ }^{1}$ Department of Oral and Maxillofacial Surgery, JSS Dental College, JSS Academy of Higher Education and Research, Mysore, \\ ${ }^{2}$ Department of Oral and Maxillofacial Surgery, Rajarajeshwari Dental College, Bangalore, India
}

\begin{abstract}
J Korean Assoc Oral Maxillofac Surg 2021;47:183-189)
Objectives: To assess the prevalence and recovery of inferior alveolar nerve dysfunction (IAND) in mandibular fractures.

Materials and Methods: This was a prospective cohort study. Clinical neurosensory testing was done preoperatively and the IAND was categorized as mild, moderate or severe. Postoperatively, neurosensory testing was repeated at 1 day, 1 week, 1 month, 3 months and every 3 months thereafter.

Results: A total of 257 patients with 420 fractures were included in the study with a mean age of 31.7 years. Body fractures (95.9\%) had the highest incidence of IAND, followed by the angle fractures $(90.1 \%)$ and symphysis fractures (27.6\%). The condyle and coronoid fractures did not have any IAND and hence were excluded from further study. After eliminating those cases, 232 patients remained in the study with 293 fractures. The overall prevalence of IAND in fractures occurring distal to the mandibular foramen was $56.3 \%$. The changes until 1 week were minimal. From 1 month to 6 months, there was a significant reduction in the severity of IAND. A significant number of cases (60.0\%) were lost to follow-up between 6 and 9 months. At 6 months, $23.9 \%$ of cases still had some form of IAND and $95.0 \%$ of the symphysis, $59.0 \%$ of the angle and $34.8 \%$ of the body fractures with IAND had become normal.
\end{abstract}

Conclusion: This study documents the reduction in the degree of severity of IAND in the first six months and provides the basis for future studies with longer periods of follow-up.

Key words: Mandibular fractures, Sensation disorders, Inferior alveolar nerve, Prevalence

[paper submitted 2020. 12. 17 / revised 2021. 2. 23 / accepted 2021. 3. 4]

\section{Introduction}

Mandibular fractures are one of the most common fractures of the facial region ${ }^{1}$. The data regarding the natural history and long-term outcomes of neurosensory deficits following maxillofacial trauma are scarce ${ }^{2}$. The inferior alveolar nerve can be damaged within the mandibular canal or after its exit from the mental foramen, either by direct trauma or from manipulation during the surgery ${ }^{3}$.

The prevalence of post-traumatic or pre-treatment inferior

\section{Chandan $S N$}

Department of Oral and Maxillofacial Surgery, JSS Dental College, JSS Academy of Higher Education and Research, SS Nagar, Mysore 570015, India

TEL: +91-9448307430

E-mail:dr.chandansn@jssuni.edu.in

ORCID: https://orcid.org/0000-0001-6011-2811

(c) This is an open-access article distributed under the terms of the Creative Commons Attribution Non-Commercial License (http://creativecommons.org/ licenses/by-nc/4.0/), which permits unrestricted non-commercial use, distribution, and reproduction in any medium, provided the original work is properly cited.

Copyright (C) 2021 The Korean Association of Oral and Maxillofacial Surgeons. All rights reserved. alveolar nerve dysfunction (IAND) after a mandibular fracture ranges from $5.7 \%$ to $58.5 \%$, and IAND after treatment ranges from $0.9 \%$ to $66.7 \%$. This large range of prevalence estimates is an indication of the lack of uniformity in both reported incidences and in the types of testing used to assess neurosensory deficit ${ }^{5}$. Clinically, there are various methods to evaluate the presence and degree of nerve injury. This can vary from just asking the patient subjectively about any neurosensory deficiency to complex clinical neurosensory testing (CNST). Subjective tests are generally unreliable, as they can reveal varied neurosensory deficits compared to objective tests ${ }^{6}$.

In 1992, Zuniga and Essick $^{7}$ described a testing algorithm for grading trigeminal nerve injuries using CNST methods. (Fig. 1) This testing algorithm is simple to apply and can be performed chairside with minimal equipment, making it a valuable tool in identifying and grading neurosensory deficits $^{8}$. A prospective study to evaluate the prevalence of neurosensory dysfunction in mandibular fractures, including preoperative and postoperative variations, and the course of recovery is hence necessary. 


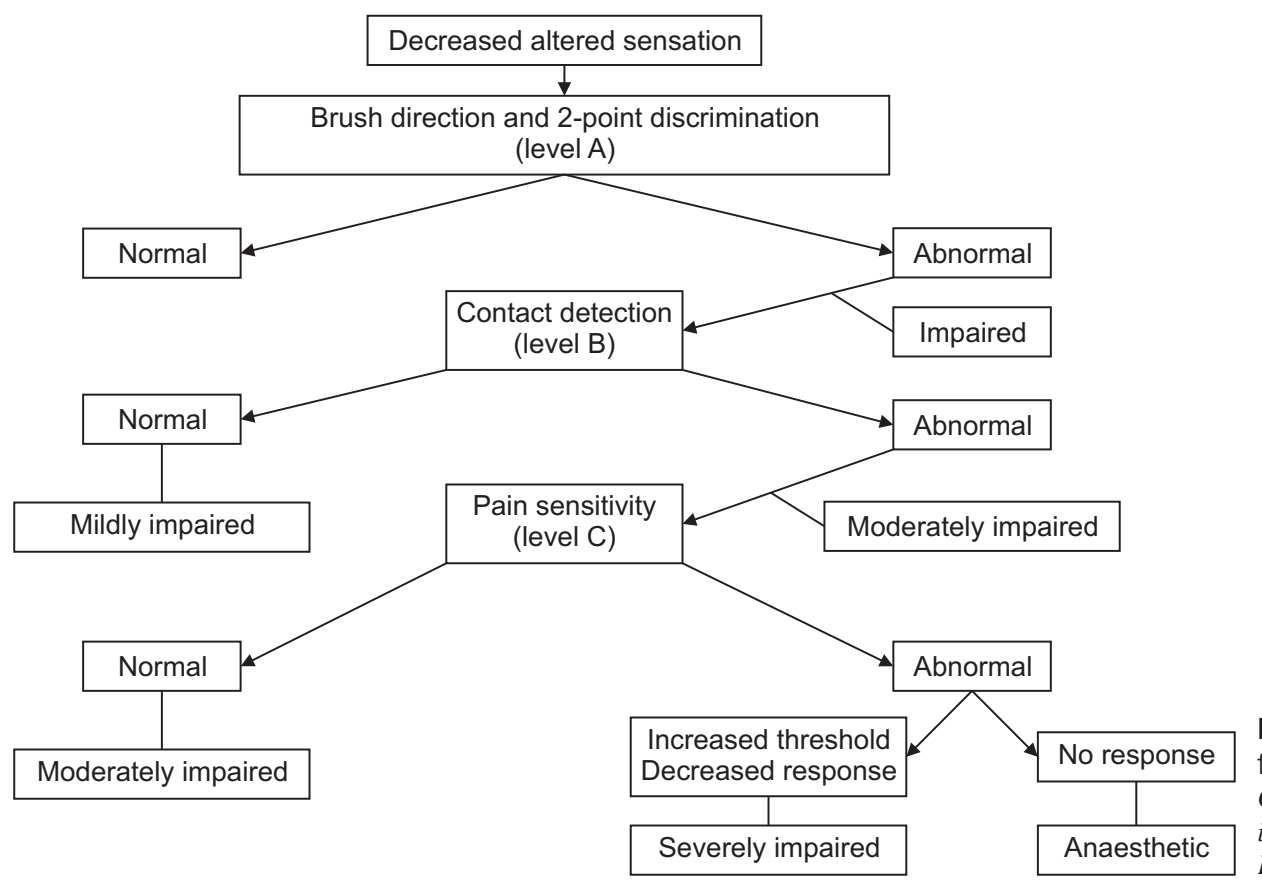

Fig. 1. Zuniga and Essick's algorithm for clinical neurosensory testing ${ }^{7}$. Chandan SN et al: Inferior alveolar nerve dusfunction in mandibular fractures: a prospective cohort study. $J$ Korean Assoc Oral Maxillofac Surg 2021

\section{Materials and Methods}

This was a prospective cohort study including patients reporting to our institution for the treatment of mandibular fractures between July 2016 and December 2019 at JSS Dental College and Hospital. All patients with mandibular fractures who were willing to participate were included in the study barring the following exclusions: 1) patients who were unable to provide an accurate assessment of sensory neurological examination, like patients with mental disabilities or those who presented with an associated head injury; 2) patients with a previous history of mandibular fractures, pathological fractures or presence of any mandibular pathology, or radiotherapy of the mandible; 3 ) patients with a history of neurosensory problems of the inferior alveolar nerve like trigeminal neuralgia, paresthesia or iatrogenic injury from extractions; and 4) patients who required extensive extra-oral incision and external fixation for the management of mandibular fractures. This study was approved by the Institutional Ethical Committee of JSS Dental College and Hospital (No. JSS/DCH/Ethical/ $\mathrm{PhD} / 2016-17(2) / 02)$. Informed consent was obtained from all patients. Mandibular fractures were categorized based on the location of the fracture into symphysis, body, angle, condyle, and coronoid fractures according to the AOCMF classification system ${ }^{9}$. CNST was performed using mechanoceptive (2-point discrimination, static light touch, brush directional stroke) and nociceptive (pinprick, thermal discrimination) methods.

1. 2-Point discrimination: A Castroviejo caliper with a millimeter ruler was used. The test begins with the caliper closed and then progressively opened in $0.5-\mathrm{mm}$ increments until the patient can discriminate 2 points (Nishioka et al. ${ }^{10}$ ). Normal measures for 2-point discrimination in the trigeminal distribution vary from $7-14 \mathrm{~mm}$; the response is considered diminished at 15-20 $\mathrm{mm}$ and absent above $20 \mathrm{~mm}$ (Campbell et al. ${ }^{11}$ ).

2. Brush directional stroke: Standardized Semmes-Weinstein monofilament (Aesthesio; Danmic Global, San Jose, CA, USA) was used. A 1-cm stroke was administered 3 times in each zone, right-left or left-right was determined according to the examiner, and the patient was asked to identify the direction.

3. Static light touch: Standardized Semmes-Weinstein monofilaments (Aesthesio) were used. Testing begins with a size 1.65 monofilament pressed towards the site until it bends. In the trigeminal nerve, a 1.65 to 2.36 monofilament size range is considered normal.

4. Pin-prick: A 24-gauge needle was used for quick pricking with an intensity sufficient to draw a small drop of blood at the puncture site.

5. Thermal discrimination: A cotton-tipped applicator (earbud) saturated with ethyl chloride was applied lightly to each facial zone, along with a placebo. The expected response was cool or cold and the patient should be able to differentiate between the placebo and the ethyl chloride.

All tests were done with the patient gently closing his/ her eyes and separating his/her lips comfortably. Each facial 
zone was tested 3 times, with 2 out of 3 correct responses considered normal. Testing of the opposite side or maxillary infraorbital region was used as a control. Nerve impairment was categorized into mild, moderate, or severe based on the grading algorithm given by Zuniga and Essick ${ }^{7}$. Assessment of neurosensory impairment was done on the preoperative day and one day postoperatively after the complete recovery of the patient from anesthesia. Follow-up assessment of neurosensory impairment was done using the above methods at one week, 1 month, 3 months and every 3 months thereafter.

Summary statistics were calculated utilizing proportions for categorical/binary variables and mean, median, standard deviation and interquartile range for continuous variables. Inferential statistics were calculated using the chi-square test or Fisher's exact test for age and sex distribution and IAND according to fracture location at various intervals. The McNemar test was used to analyze the IAND change from preoperative day to 1 day, 1 week, 1 month, 3 months and 6 months after surgery. Cochrane's Q test was used to analyze the overall IAND at each time point. All statistical methods were performed using IBM SPSS Statistics for Windows (ver. 21.0; IBM, Armonk, NY, USA). A P-value less than 0.05 was considered statistically significant.

\section{Results}

In total, 257 patients were included in the study including 227 males $(88.3 \%)$ and 30 females (11.7\%). The mean age of the patients was 31.7 years. The 257 patients had a total of 420 fractures (average of 1.6 fractures per patient). The fractures were classified according to their anatomical locations and the majority of the fractures; 163 (38.8\%) were in the symphysis region, followed by 122 condylar fractures $(29.0 \%), 81$ angle fractures (19.3\%), 49 body fractures (11.7\%), and 5 coronoid fractures (1.2\%). Out of 420 fractures, 255 fractures $(60.7 \%)$ had no IAND and 165 had some degree of IAND, for an overall prevalence of $39.3 \%$ of neurosensory dysfunction in mandibular fractures. In our study, we found that none of the condylar or coronoid fractures had IAND. The further inclusion of these two regions in the study would dilute the results. After excluding the condylar and coronoid fractures, 293 fractures in 232 patients were included for further analysis. The etiologies of the fractures were road traffic accidents (78.4\%), self-falls (12.5\%), assaults (6.2\%), and industrial accidents $(2.9 \%)$. One 75 -year-old patient was treated using her denture as a gunning splint with circumandibular wiring. Intermaxillary fixation was used as a treatment in 21 fractures (7.2\%), and 270 fractures $(92.2 \%)$ were treated with open reduction and internal fixation (ORIF).(Table 1)

Overall, 165 out of 293 fractures had some form of IAND, for a prevalence of $56.3 \%$ of post-trauma (pre-treatment) IAND in the fractures occurring distal to the mandibular foramen. Body fractures had the highest incidence of IAND $(95.9 \%)$, followed by angle fractures $(90.1 \%)$ and symphysis fractures $(27.6 \%)$. When the severity of the IAND was assessed preoperatively, $37.2 \%$ of fractures had severe IAND,

Table 1. Preoperative inferior alveolar nerve dysfunction (IAND) according to age, sex, fracture location and treatment

\begin{tabular}{|c|c|c|c|c|}
\hline \multirow{2}{*}{\multicolumn{2}{|c|}{ Variable }} & \multirow{2}{*}{$\mathrm{n}(\%)$} & \multicolumn{2}{|c|}{ Preoperative IAND } \\
\hline & & & Absent & Present \\
\hline Age category $(n=232)$ & $\begin{array}{l}<20 \mathrm{yr} \\
21-40 \mathrm{yr} \\
>41 \mathrm{yr}\end{array}$ & $\begin{array}{r}24(10.3) \\
163(70.3) \\
45(19.4)\end{array}$ & $\begin{array}{l}11(45.8) \\
59(36.2)\end{array}$ & $\begin{array}{r}13(54.2) \\
104(63.8) \\
28(62 .)\end{array}$ \\
\hline $\mathrm{df}=2, \chi^{2}=0.831, P=0.660$ & & & & \\
\hline $\operatorname{Sex}(n=232)$ & $\begin{array}{l}\text { Male } \\
\text { Female } \\
\text { Total }\end{array}$ & $\begin{array}{r}207(89.2) \\
25(10.8)\end{array}$ & $\begin{array}{l}75(36.2) \\
12(48.0) \\
87(37.5)\end{array}$ & $\begin{array}{r}132(63.8) \\
13(52.0) \\
145(62.5)\end{array}$ \\
\hline $\mathrm{df}=1, \chi^{2}=1.318, P=0.251$ & & & & \\
\hline Fracture $(n=293)$ & $\begin{array}{l}\text { Angle } \\
\text { Body } \\
\text { Symphysis }\end{array}$ & $\begin{array}{r}81(27.6) \\
49(16.7) \\
163(55.6)\end{array}$ & $\begin{array}{r}8(9.9) \\
2(4.1) \\
118(72.4) \\
128(43.7)\end{array}$ & $\begin{array}{r}73(90.1) \\
47(95.9) \\
45(27.6) \\
165(56.3)\end{array}$ \\
\hline Treatment $(n=293)$ & ORIF & $270(92.2)$ & $111(41.1)$ & $159(58.9)$ \\
\hline & Circumandibular wiring & $1(0.3)$ & $\begin{array}{c}16(76.2) \\
0(0)\end{array}$ & $1(100)$ \\
\hline & DAMA & $1(0.3)$ & $1(100)$ & $0(0)$ \\
\hline & Total & & $128(43.7)$ & $165(56.3)$ \\
\hline Etiology & Road traffic accidents & & $78.4 \%$ & \\
\hline & Self-falls & & $12.5 \%$ & \\
\hline & Assaults & & $6.2 \%$ & \\
\hline & Industrial accidents & & $2.9 \%$ & \\
\hline
\end{tabular}

(df: degree of freedom, ORIF: open reduction and internal fixation, IMF: intermaxillary fixation, DAMA: discharged against medical advice) Values are presented as number (\%) or $\%$.

Chandan SN et al: Inferior alveolar nerve dysfunction in mandibular fractures: a prospective cohort study. J Korean Assoc Oral Maxillofac Surg 2021 
$6.1 \%$ had moderate IAND and $13.0 \%$ had mild IAND. In our study, there were minimal changes perioperatively. Three cases $(1.1 \%)$ improved whereas three $(1.1 \%)$ worsened. Out of the three cases which worsened, all had ORIF as the treatment and all were in the symphysis region.

At one month postoperative, the symphysis region showed the highest recovery, with almost half of the patients returning to normalcy. Many cases among angle and body fractures were also reduced in severity. At 3 months, symphysis fractures continued to recover well, with $91.9 \%$ returning to normal. Angle and body fractures also showed a significant $(P<0.0001)$ reduction in severity. At 6 months, $95.0 \%$ of the IAND in symphysis fractures had become normal. The majority of angle fractures (59.0\%) had become normal, whereas $29.5 \%$ had mild IAND. Body fractures showed the least recovery, with only $34.8 \%$ normalcy.(Table 2 ) At the end of 6 months, 70 fracture sites had IAND, out of which $42(60.0 \%)$ were lost to follow-up by 9 months. Hence, the overall analysis in our study was limited to a 6-month period to avoid any selection bias.

Changes in IAND between consecutive follow-ups were compared.(Fig. 2) There was no significant change $(P=0.223)$ from preoperative day to the first postoperative day. From one day to one week postoperative, there were very few changes but the changes were significant $(P=0.007)$. The changes from 1 week to 1 month, 1 month to 3 months and 3 months to 6 months were very significant $(P<0.0001)$. At 6 months, there were 15 cases $(5.3 \%)$ with severe IAND, 10 cases $(3.5 \%)$ with moderate IAND and 45 cases $(15.8 \%)$ with mild IAND.(Table 3) At 6 months, 9 patients (3.3\%) were lost to follow-up, and a total of 214 cases $(75.4 \%)$ were normal. In our study, at the end of 6 months, $23.9 \%$ of cases still had some degree of IAND.(Table 4)

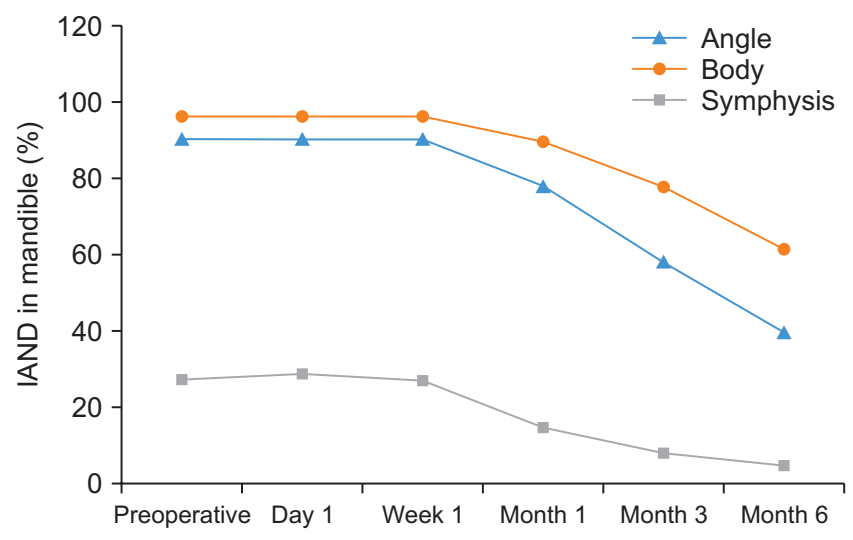

Fig. 2. Inferior alveolar nerve dysfunction (IAND) over time in relation to fracture location.

Chandan $S N$ et al: Inferior alveolar nerve dysfunction in mandibular fractures: a prospective cohort study. J Korean Assoc Oral Maxillofac Surg 2021

Table 2. Changes in inferior alveolar nerve dysfunction severity over 6 months according to fracture location

\begin{tabular}{|c|c|c|c|c|c|c|c|c|}
\hline \multirow{2}{*}{ Fracture } & \multicolumn{2}{|c|}{ Normal } & \multicolumn{2}{|c|}{ Mild } & \multicolumn{2}{|c|}{ Moderate } & \multicolumn{2}{|c|}{ Severe } \\
\hline & Count & $\%$ & Count & $\%$ & Count & $\%$ & Count & $\%$ \\
\hline \multicolumn{9}{|l|}{ Preoperative } \\
\hline Angle & 8 & 9.9 & 13 & 16.0 & 10 & 12.3 & 50 & 61.7 \\
\hline Body & 2 & 4.1 & 1 & 2.0 & 2 & 4.1 & 44 & 89.8 \\
\hline Symphysis & 118 & 72.4 & 24 & 14.7 & 6 & 3.7 & 15 & 9.2 \\
\hline Total & 128 & 43.7 & 38 & 13.0 & 18 & 6.1 & 109 & 37.2 \\
\hline \multicolumn{9}{|l|}{ Day 1} \\
\hline Angle & 8 & 9.9 & 14 & 17.3 & 9 & 11.1 & 50 & 61.7 \\
\hline Body & 2 & 4.1 & 1 & 2.0 & 2 & 4.1 & 44 & 89.8 \\
\hline Symphysis & 115 & 71.0 & 27 & 16.7 & 5 & 3.1 & 15 & 9.3 \\
\hline Total & 125 & 42.8 & 42 & 14.4 & 16 & 5.5 & 109 & 37.3 \\
\hline \multicolumn{9}{|l|}{ Week 1} \\
\hline Angle & 8 & 9.9 & 18 & 22.2 & 7 & 8.6 & 48 & 59.3 \\
\hline Body & 2 & 4.1 & 1 & 2.0 & 2 & 4.1 & 44 & 89.8 \\
\hline Symphysis & 118 & 72.8 & 27 & 16.7 & 2 & 1.2 & 15 & 9.3 \\
\hline Total & 128 & 43.8 & 46 & 15.8 & $1 \overline{1}$ & 3.8 & 107 & 36.6 \\
\hline \multicolumn{9}{|l|}{ Month 1} \\
\hline Angle & 15 & 19.2 & 23 & 29.5 & 13 & 16.7 & 27 & 34.6 \\
\hline Body & 2 & 4.3 & 7 & 15.2 & 10 & 21.7 & 27 & 58.7 \\
\hline Symphysis & 138 & 85.2 & 14 & 8.6 & 3 & 1.9 & 7 & 4.3 \\
\hline Total & 155 & 54.2 & 44 & 15.4 & 26 & 9.1 & 61 & 21.3 \\
\hline \multicolumn{9}{|l|}{ Month 3} \\
\hline Angle & 31 & 39.7 & 26 & 33.3 & 10 & 12.8 & 11 & 14.1 \\
\hline Body & 8 & 17.4 & 13 & 28.3 & 7 & 15.2 & 18 & 39.1 \\
\hline Symphysis & 148 & 91.9 & 7 & 4.3 & 2 & 1.2 & 4 & 2.5 \\
\hline Total & 187 & 65.6 & 46 & 16.1 & 19 & 6.7 & 33 & 11.6 \\
\hline \multicolumn{9}{|l|}{ Month 6} \\
\hline Angle & 46 & 59.0 & 23 & 29.5 & 4 & 5.1 & 5 & 6.4 \\
\hline Body & 16 & 34.8 & 17 & 37.0 & 4 & 8.7 & 9 & 19.6 \\
\hline Symphysis & 152 & 95.0 & 5 & 3.1 & 2 & 1.3 & 1 & 0.6 \\
\hline Total & 214 & 75.4 & 45 & 15.8 & 10 & 3.5 & 15 & 5.3 \\
\hline
\end{tabular}

Chandan S N et al: Inferior alveolar nerve dysfunction in mandibular fractures: a prospective cohort study. J Korean Assoc Oral Maxillofac Surg 2021 


\section{Discussion}

The inferior alveolar nerve is well protected inside the mandibular canal. But, in mandibular fractures, this position of the nerve itself will endanger its integrity. The data regarding the IAND in mandibular fractures are variably documented in the literature ${ }^{4}$. Studies are either retrospective in nature ${ }^{5,12,13}$ or have small sample sizes ${ }^{14,15}$. There is no uniformity in the assessment of IAND according to anatomical location, as most studies have considered only the nerve-bearing area between the lingula and mental foramen ${ }^{5,12,16}$, which omits the fractures in the symphysial region. Varying sensory assessment methods have been tried, including subjective assessments or questionnaire surveys ${ }^{5}$, objective $\mathrm{CNST}^{2,8}$ and advanced NST methods ${ }^{17}$. Ghali and Epker ${ }^{18}$ recommended in their practical applications of CNST that the clinicians conducting CNST should conduct 2-point discrimination, static light touch, brush directional stroke, pinprick and thermal discrimination in that order. Zuniga and Essick ${ }^{7}$ gave an algorithm that categorizes the nerve dysfunction into mild, moderate and severe based on CNST. Adapting this protocol for CNST would result in better standardization in future studies.

The 257 patients in our study had 420 fractures among them, with an average of 1.6 fractures per patient. In the study by Ellis et al. ${ }^{1}, 3,462$ fractures were present in 2,137 mandibles, for an average of 1.6 fractures per mandible. When IAND was assessed in the 420 fractures of our study, 255 fractures $(60.7 \%)$ had no IAND, for an overall prevalence of IAND in mandibular fractures of $39.3 \%$. In our study, condylar and coronoid fractures did not have any IAND, which was an expected finding, as the inferior alveolar nerve (IAN) enters the mandibular foramen near the lingula beyond this region. Hence, only the fractures distal to the mandibular foramen were included in our study. Many of these patients had bilateral fractures with bilateral IAND; hence, calculating the prevalence per patient was not ideal. Poort et al. ${ }^{17}$, in

Table 4. Overall inferior alveolar nerve dysfunction (IAND) at each time point $(n=293)$

\begin{tabular}{lc}
\hline \multicolumn{1}{c}{ IAND } & $\mathrm{n}(\%)$ \\
\hline Preoperative & $165(56.3)$ \\
Day 1 & $167(57.0)$ \\
Week 1 & $164(56.0)$ \\
Month 1 & $131(44.7)$ \\
Month 3 & $98(33.4)$ \\
Month 6 & $70(23.9)$ \\
df=5, Cochran's Q=316.098 (1 is treated as a success), $P<0.0001$ \\
\hline
\end{tabular}

(df: degree of freedom)

Chandan S N et al: Inferior alveolar nerve dysfunction in mandibular fractures: a prospective cohort study. J Korean Assoc Oral Maxillofac Surg 2021

Table 3. Changes in inferior alveolar nerve dysfunction severity over 6 months

\begin{tabular}{|c|c|c|c|c|c|c|c|c|c|}
\hline & & \multicolumn{2}{|c|}{ Normal } & \multicolumn{2}{|c|}{ Mild } & \multicolumn{2}{|c|}{ Moderate } & \multicolumn{2}{|c|}{ Severe } \\
\hline & & Count & $\%$ & Count & $\%$ & Count & $\%$ & Count & $\%$ \\
\hline \multirow{5}{*}{ Preoperative } & Day 1 & & & & & & & & \\
\hline & Normal & 125 & 98.4 & 2 & 1.6 & 0 & 0 & 0 & 0 \\
\hline & Mild & 0 & 0 & 37 & 97.4 & 1 & 2.6 & 0 & 0 \\
\hline & Moderate & 0 & 0 & 3 & 16.7 & 15 & 83.3 & 0 & 0 \\
\hline & Severe & 0 & 0 & 0 & 0 & 0 & 0 & 109 & 100 \\
\hline \multirow{2}{*}{\multicolumn{10}{|c|}{$\mathrm{n}=292, \mathrm{df}=2, \mathrm{McNemar}-$ Bowker value $=3.000, P=0.223$}} \\
\hline & & & & & & & & & \\
\hline \multirow{4}{*}{ Day 1} & Normal & 125 & 100.0 & 0 & 0 & 0 & 0 & 0 & 0 \\
\hline & Mild & 3 & 7.1 & 39 & 92.9 & 0 & 0 & 0 & 0 \\
\hline & Moderate & 0 & 0 & 7 & 43.8 & 9 & 56.3 & 0 & 0 \\
\hline & Severe & 0 & 0 & 0 & 0 & 2 & 1.8 & 107 & 98.2 \\
\hline \multirow{2}{*}{\multicolumn{10}{|c|}{$\begin{array}{l}\mathrm{n}=292, \mathrm{df}=3, \text { McNemar-Bowker value }=12.000, P=0.007 \\
\text { Week 1 }\end{array}$}} \\
\hline & & & & & & & & & \\
\hline \multirow{4}{*}{ Week 1} & Normal & 128 & 100 & 0 & 0 & 0 & 0 & 0 & 0 \\
\hline & Mild & 24 & 52.2 & 22 & 47.8 & 0 & 0 & 0 & 0 \\
\hline & Moderate & 2 & 18.2 & 6 & 54.5 & 3 & 27.3 & 0 & 0 \\
\hline & Severe & 1 & 1.0 & 16 & 15.8 & 23 & 22.8 & 61 & 60.4 \\
\hline \multicolumn{10}{|c|}{$\mathrm{n}=286, \mathrm{df}=6$, McNemar-Bowker value $=72.000, P<0.0001$} \\
\hline \multicolumn{10}{|c|}{ Month $1 \quad$ Month 3} \\
\hline & Normal & 155 & 100 & 0 & 0 & 0 & 0 & 0 & 0 \\
\hline & Mild & 24 & 54.5 & 20 & 45.5 & 0 & 0 & 0 & 0 \\
\hline & Moderate & 6 & 24.0 & 10 & 40.0 & 9 & 36.0 & 0 & 0 \\
\hline & Severe & 2 & 3.3 & 16 & 26.2 & 10 & 16.4 & 33 & 54.1 \\
\hline \multirow{2}{*}{\multicolumn{10}{|c|}{$\begin{array}{l}\mathrm{n}=285, \mathrm{df}=6, \text { McNemar-Bowker value }=68.000, P<0.0001 \\
\text { Month } 3\end{array}$}} \\
\hline & & & & & & & & & \\
\hline & Normal & 187 & 100 & 0 & 0 & 0 & 0 & 0 & 0 \\
\hline & Mild & 24 & 52.2 & 22 & 47.8 & 0 & 0 & 0 & 0 \\
\hline & Moderate & 3 & 15.8 & 14 & 73.7 & 2 & 10.5 & 0 & 0 \\
\hline & Severe & 0 & 0 & 9 & 28.1 & 8 & 25.0 & 15 & 46.9 \\
\hline \multicolumn{10}{|c|}{$\mathrm{n}=284, \mathrm{df}=5$, McNemar-Bowker value $=58.000, P<0.0001$} \\
\hline
\end{tabular}

(df: degree of freedom)

Chandan S N et al: Inferior alveolar nerve dysfunction in mandibular fractures: a prospective cohort study. J Korean Assoc Oral Maxillofac Surg 2021 
their systematic review of sensory testing of IAN injuries, recommended calculating the incidence of IAND per treated side and differentiating between bilateral and unilateral nerve injuries. A total of 165 out of 293 fractures had IAND for an overall prevalence of $56.3 \%$. If only the inferior alveolar nerve-bearing area (body and angle fractures) is considered, the prevalence in our study was very high at $93.0 \%$. This was similar to that given by Yadav et al. ${ }^{19}$ of $86.7 \%$. According to the review by Thurmüller et al. ${ }^{4}$, the post-traumatic, pre-treatment nerve injury considering only angle and body fractures ranged from $46 \%$ to $58.5 \%$, but the same study reported overall postoperative IAND to be in the range of $0.4 \%$ to $91.3 \%$, or between $76.1 \%$ and $91.3 \%$ when only nerve-bearing area were considered. In our study, road traffic accidents were the major etiological factor, and these high-velocity injuries may have resulted in an increased incidence of IAND.

In our study, there were very few changes in the IAND on the postoperative day, except for improvement in three cases and exacerbation in three cases. Iizuka and Lindqvist ${ }^{3}$, in their study on sensory disturbances associated with rigid internal fixation, mentioned that the IAND increased from 58.5\% preoperatively to $91.3 \%$ in the immediate postoperative period. Song et al. ${ }^{12}$, in their study on IAN and mental nerve injuries associated with ORIF, found the IAN status was unchanged in $87 \%$ of cases. Schultze-Mosgau et al. ${ }^{20}$ observed in their prospective study that IAND increased from $46 \%$ preoperatively to $76.9 \%$ postoperatively. One probable reason for not seeing a large increase in IAND postoperatively in our study could be that our preoperative IAND in angle and body fractures was already high at $93 \%$.

The changes from the first postoperative day to 1 week postoperative were minimal. One week is not enough time for any major changes to occur. At the end of 3 months, $63.8 \%$ of cases had become normal. Schultze-Mosgau et al. ${ }^{20}$ had observed in their study that significant IAND recovery happened between the fourth week and third month postoperatively. At 6 months, 95\% of the IAND in symphysis fractures had become normal. Often, IAND in symphysis fractures can be from blunt trauma or the manipulation of the IAN during ORIF at the region of its exit from the mental foramen and was not caused by the bony fracture itself. Most of these cases probably had some form of neuropraxia or nerve compression, which are resolved either by the fracture management and stability or by a decrease in perineural edema. Body fractures showed the least recovery at six months, with $34.8 \%$ having normal IAN function and $19.6 \%$ of fractures still having severe IAND. Tay et al. ${ }^{8}$ observed in their study that IAND in the non-nerve-bearing sites was favorable to normalization compared to that of the nerve-bearing sites, where the time to normalization was much longer.

In this study, we assessed the natural course of recovery after IAND. At the end of 6 months, there were still 23.9\% cases with some form of IAND including $15.4 \%$ mild, $3.4 \%$ moderate and $5.1 \%$ severe cases. The mean age of the patients who had IAND at 6 months was 34 years, an increase from 31.7 years preoperatively, which indicates that advanced age was a contributing factor for slower recovery from IAND. The exact prevalence of permanent IAND after mandibular fractures is not certain. Marchena et al. ${ }^{5}$ have reported a high proportion of permanent IAND even after a mean follow-up of 6 years. In our study, a significant number of patients were lost to follow-up after 6 months. Tay et al. ${ }^{8}$ recommended nerve repair procedures after a 3- to 6-month period. However, it is not clear from the literature at what time it would be appropriate to consider a nerve repair procedure. In our study, 15 cases $(5.1 \%)$ remained with severe IAND at the 6-month follow-up. These cases may be candidates for nerve repair.

Although our study was comprehensive, it still had certain limitations. We did not study all the neurosensory disturbances in mandibular fractures like paresthesia, dysesthesia and hyperesthesia. Hypoesthesia, being more common, was the main focus of this study. Secondly, fracture displacement was not correlated with IAND. It has been well documented in many studies that fracture displacement does have a higher correlation with nerve dysfunction ${ }^{3,4}$. Our study had a large sample size, and a variety of radio-diagnostic tools were used before fracture management like orthopantomograms, computed tomography scans and lateral extraoral radiography. This made it difficult to standardize the analysis of fracture displacement.

\section{Conclusion}

This study included standardized clinical neurosensory testing methods and a severity grading protocol, resulting in a reliable assessment of IAND in mandibular fractures. This was particularly helpful in understanding the natural course of recovery of IAND. This study documents the reduction in the degree of severity of IAND in the first six months and provides the basis for future studies with a longer follow-up period. 


\section{ORCID}

Chandan S N, https://orcid.org/0000-0001-6011-2811

Sujeeth Kumar Shetty, https://orcid.org/0000-0002-8163-3904

Sahith Kumar Shetty, https://orcid.org/0000-0002-4665-2093

Anjan Kumar Shah, https://orcid.org/0000-0001-7986-1820

\section{Authors' Contributions}

C.S.N. performed data analysis and manuscript preparation. S.K.S. (Sujeeth Kumar Shetty) developed the conceptual idea. S.K.S. (Sahith Kumar Shetty) helped with review and references. A.K.S. helped in manuscript review and editing. All authors have read and approved the final version of the manuscript.

\section{Ethics Approval and Consent to Participate}

This study was approved by the Institutional Ethical Committee of JSS Dental College and Hospital (No. JSS/DCH/ Ethical/PhD/2016-17(2)/02). Informed consent was obtained from all patients.

\section{Conflict of Interest}

No potential conflict of interest relevant to this article was reported.

\section{References}

1. Ellis E 3rd, Moos KF, el-Attar A. Ten years of mandibular fractures: an analysis of 2,137 cases. Oral Surg Oral Med Oral Pathol 1985;59:120-9. https://doi.org/10.1016/0030-4220(85)90002-7

2. Halpern LR, Kaban LB, Dodson TB. Perioperative neurosensory changes associated with treatment of mandibular fractures. J Oral Maxillofac Surg 2004;62:576-81. https://doi.org/10.1016/ j.joms.2003.12.006

3. Iizuka T, Lindqvist C. Sensory disturbances associated with rigid internal fixation of mandibular fractures. J Oral Maxillofac Surg 1991;49:1264-8. https://doi.org/10.1016/0278-2391(91)90301-2

4. Thurmüller P, Dodson TB, Kaban LB. Nerve injuries associated with facial trauma: natural history, management, and outcomes of repair. Oral Maxillofac Surg Clin N Am 2001;13:283-93. https:// doi.org/10.1016/S1042-3699(20)30144-8

5. Marchena JM, Padwa BL, Kaban LB. Sensory abnormalities associated with mandibular fractures: incidence and natural history. J Oral Maxillofac Surg 1998;56:822-5; discussion 825-6. https://doi. org/10.1016/s0278-2391(98)90003-9

6. Coghlan KM, Irvine GH. Neurological damage after sagittal split osteotomy. Int J Oral Maxillofac Surg 1986;15:369-71. https://doi. org/10.1016/s0300-9785(86)80023-0
7. Zuniga JR, Essick GK. A contemporary approach to the clinical evaluation of trigeminal nerve injuries. Oral Maxillofac Surg Clin N Am 1992;4:353-67. https://doi.org/10.1016/S10423699(20)30593-8

8. Tay AB, Lai JB, Lye KW, Wong WY, Nadkarni NV, Li W, et al. Inferior alveolar nerve injury in trauma-induced mandible fractures. J Oral Maxillofac Surg 2015;73:1328-40. https://doi.org/10.1016/ j.joms.2015.02.003

9. Cornelius CP, Audigé L, Kunz C, Rudderman R, Buitrago-Téllez CH, Frodel J, et al. The comprehensive AOCMF classification system: mandible fractures- level 2 tutorial. Craniomaxillofac Trauma Reconstr 2014;7(Suppl 1):S015-30. https://doi.org/10.1055/s-0034-1389557

10. Nishioka GJ, Zysset MK, Van Sickels JE. Neurosensory disturbance with rigid fixation of the bilateral sagittal split osteotomy. J Oral Maxillofac Surg 1987;45:20-6. https://doi.org/10.1016/02782391(87)90081-4

11. Campbell RL, Shamaskin RG, Harkins SW. Assessment of recovery from injury to inferior alveolar and mental nerves. Oral Surg Oral Med Oral Pathol 1987;64:519-26. https://doi. org/10.1016/0030-4220(87)90024-7

12. Song Q, Li S, Patil PM. Inferior alveolar and mental nerve injuries associated with open reduction and internal fixation of mandibular fractures: a seven year retrospective study. J Craniomaxillofac Surg 2014;42:1378-81. https://doi.org/10.1016/j.jcms.2014.03.029

13. Boffano P, Roccia F, Gallesio C, Karagozoglu K, Forouzanfar T. Inferior alveolar nerve injuries associated with mandibular fractures at risk: a two-center retrospective study. Craniomaxillofac Trauma Reconstr 2014;7:280-3. https://doi.org/10.1055/s-0034-1375169

14. Mayrink G, Moreira RW, Araujo MM. Prospective study of postoperative sensory disturbances after surgical treatment of mandibular fractures. Oral Maxillofac Surg 2013;17:27-31. https://doi. org/10.1007/s10006-012-0328-7

15. Lone P, Kouser T, Gandral A. Response of inferior alveolar nerve to mandibular angle fractures. JK Sci 2014;16:62-6.

16. Bede SY, Ismael WK, Al-Assaf DA, Omer SS. Inferior alveolar nerve injuries associated with mandibular fractures. J Craniofac Surg 2012;23:1776-8. https://doi.org/10.1097/ SCS.0b013e318266fda3

17. Poort LJ, van Neck JW, van der Wal KG. Sensory testing of inferior alveolar nerve injuries: a review of methods used in prospective studies. J Oral Maxillofac Surg 2009;67:292-300. https://doi. org/10.1016/j.joms.2008.06.076

18. Ghali GE, Epker BN. Clinical neurosensory testing: practical applications. J Oral Maxillofac Surg 1989;47:1074-8. https://doi. org/10.1016/0278-2391(89)90184-5

19. Yadav S, Mittal HC, Malik S, Dhupar V, Sachdeva A, Malhotra V, et al. Post-traumatic and postoperative neurosensory deficits of the inferior alveolar nerve in mandibular fracture: a prospective study. J Korean Assoc Oral Maxillofac Surg 2016;42:259-64. https://doi. org/10.5125/jkaoms.2016.42.5.259

20. Schultze-Mosgau S, Erbe M, Rudolph D, Ott R, Neukam FW. Prospective study on post-traumatic and postoperative sensory disturbances of the inferior alveolar nerve and infraorbital nerve in mandibular and midfacial fractures. J Craniomaxillofac Surg 1999;27:86-93. https://doi.org/10.1016/s1010-5182(99)80019-5

How to cite this article: Chandan SN, Shetty SK, Shetty SK, Shah AK. Inferior alveolar nerve dysfunction in mandibular fractures: a prospective cohort study. J Korean Assoc Oral Maxillofac Surg 2021;47:183-189. https://doi.org/10.5125/jkaoms.2021.47.3.183 